\title{
METATARSALGIA: ETIOLOGY AND TREATMENT
}

\author{
By: A. C. FISHER O.B.E., M.D., F.R.C.S. \\ Chief Medical Officer, Roan Antelope Copper Mine Hospital, Luanshya, N. Rhodesia.
}

$\mathbf{M}$

ANY chronic foot ailments are due to the use of shoes. The African villager, who has so far escaped this "blessing," is singularly free from painful feet. However odd their shape, such feet are supple and toe movements free. Our civilised man gets much of his painful feet from joint rigidity and functionless toes.

Morton's Metatarsalgia has teen attributed to the collapse of the anterior transverse arch of the foot which is supposed to lead to compression of the digital nerves. However, many Surgeons believe that the anterior transverse arch of the foot is an anatomical fiction and it certainly is not to be seen in the bare-footed walker. That is why methods of treatment aimed at reconstituing this arch give uniformly poor results.

- For more than a decade the writer has based treatment on the following considerations:-

(1) The foot at the line of the heads of the metatarsals is flat in transection.

(2) All the toes are capable of strong plantar flexion so that the knuckles stand out prominently. This is most marked in the hallux, but is only slightly less so in the second, third and fourth toes.

(3) In walking the foot does not passively roll forward on the metatarsal pad, but, as the body passes the vertical, the toes flex strongly, taking much of the weight off the metatarsals so that the area which bears the thrust of the stride includes the pads of all the toes, particularly the first, second and third, as well as the metatarsal pad.

(4) A study of the tracks of a barefooted walker in soft ground shows by the deep impression of the toes how strongly they engage in the act of thrusting the body forward.

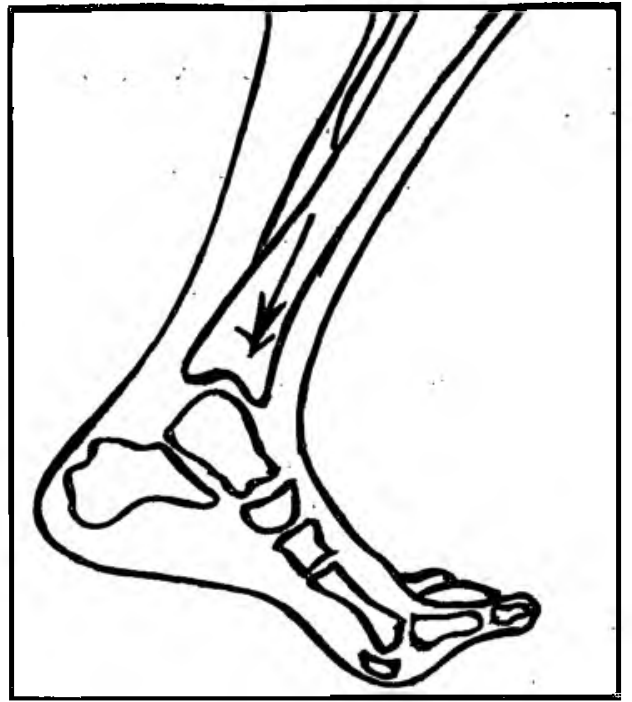

Fig. 1.: Incorrect thrust not using toe-flexors.
In every case of metatarsalgia that I have examined, plantar flexion of the toes is absent or greatly diminished. When the condition is unilateral the power of flexion on the sound side is always markedly greater than on the affected side. When a step is taken off the affected foot the whole thrust of the stride is borne by the metatarsal heads and the overlying pad. It is not surprising that the nerves suffer from pressure, particularly as the weighted foot rolls forward on the metatarsal heads, contributing a grinding action to the weight effect. As in all foot deformities, the tolerance of the individual to an abnormal state differs widely, so that metatarsalgia appears in one individual when the condition is only slightly developed, while another will tolerate a much greater degree of deformity.

Treatment:

From what has already been said it will be clear that the treatment of metatarsalgia should be directed towards recovering the power of flexion in the toes and towards re-education in the proper use of the toes in walking. (1) The patient should be directed to plantar-flex his toe repeatedly at the metatarsal heads in such a manner that the heads are lifted clear of the ground; this simple exercise can and should be done at any odd moment such as when standing waiting for a bus. (2) He should be instructed to kick off with his toes at each stride and not let the toes bend up passively; this has to be done consciously at first, but becomes a habit later. The metatarsal bar is contraindicated because it leaves the toes more helpless than ever, and other pads and straps have a similar adverse effect. Fortunately, it is possible for the toes to recover their mobility after a great many years, and I have had successes in cases of 10 and 15 years' standing where the patient was intelligent and persistent.

No doubt the foregoing argument represents an oversimplification of the problem of Metatarsalgia. Nevertheless the methods advocated above can be relied upon to give good results in a large proportion of cases.

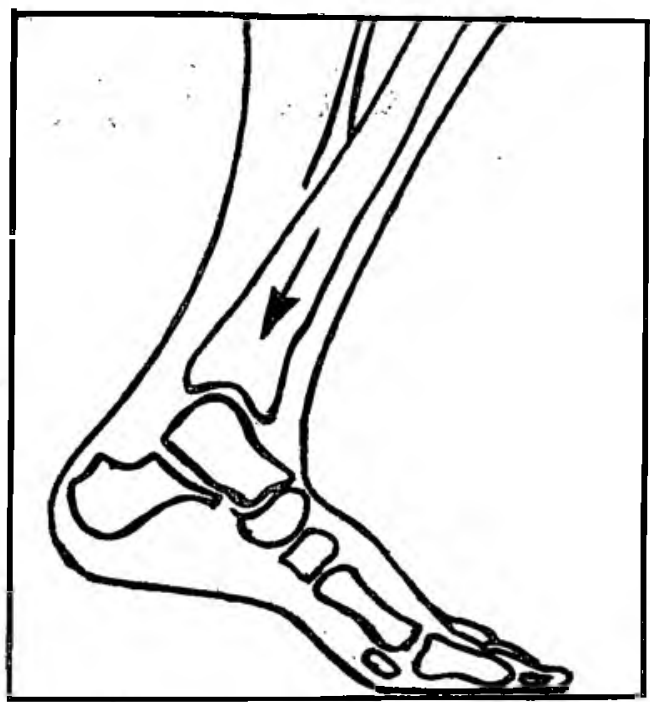

Fig. 2.: Correct use of toe-flexors. 